\title{
IDENTIFICAÇÁO DAS PRÁTICAS DA FILOSOFIA LEAN CONSTRUCTION EM CONSTRUTORAS DE MÉDIO PORTE NA CIDADE DE ITABUNA (BA)
}

\author{
Juliana Silva Rezende \\ Stella Maris Peluzio Sá Domingues² \\ Aline Patricia Mano ${ }^{3}$
}

\begin{abstract}
Resumo: Diante das exigências do mercado da construção civil e da concorrência, as empresas do ramo buscam novos processos, produtos e ferramentas para execução de obras. A Lean Construction é uma filosofia que vem sendo aplicada pelas empresas para melhorar seus processos e aperfeiçoar seus fluxos. O objetivo deste trabalho é identificar nas construtoras da cidade de Itabuna a utilização de práticas da Lean Construction e em caso afirmativo apresentar as principais práticas encontradas. Para alcançar esse objetivo é apresentada a análise de quatro empresas construtoras de edificaçôes verticais, de médio porte, localizadas na cidade de Itabuna- BA. Os resultados mostram que as empresas consultadas buscam atingir o que acredita serem os princípios da Lean Construction, mesmo que isso não seja feito intencionalmente, já que não utilizam de tal metodologia como gestão.
\end{abstract}

Palavras-chave: Lean Production, construção civil, lean construction.

\begin{abstract}
Facing the demands of the civil construction and the competition, the construction companies are looking for new processes, products and tools to execute his projects. The Lean Construction is a philosophy that is being applied by companies to improve their processes, optimize flows and increase the quality of their products. The objective of this study is to identify in builders companies of the city of Itabuna the use of Lean Construction practices and in affirmative case present the main practices found. To achieve this goal is presented the analysis of four construction companies building vertical, midsize, located in the city of Itabuna-BA. The results shows that the surveyed companies seek to achieve what the principles of Lean Construction believes, even though this is not done intentionally, since no they use this methodology as management model.
\end{abstract}

Keywords: Lean Production, civil construction, lean construction.

UESC/ Universidade Estadual de Santa Cruz, Ilhéus, BA. e-mail: julianarezende_eps@hotmail.com

2 UESC/ Universidade Estadual de Santa Cruz, Ilhéus, BA. e-mail: stelladomingues@gmail.com

3 UESC/ Universidade Estadual de Santa Cruz, Ilhéus, BA. e-mail: alinepatricia07@hotmail.com 


\section{INTRODUÇÃO}

O desenvolvimento esperado para o país nos próximos anos depende necessariamente da indústria da construçáo civil. As perspectivas positivas são baseadas em vários fatores: a necessidade da continuidade de crescimento de crédito imobiliário e de mercado habitacional, para atender ao déficit e a uma demanda crescente de moradias; o Programa Minha Casa, Minha Vida 2; o Programa de Aceleraçáo do Crescimento 2; a realização da Copa do Mundo em 2014; e a realização das olímpiadas em 2016 certamente movimentarão a extensa cadeia produtiva do setor, gerando empregos e distribuindo renda por toda economia (CBIC, 2011).

A indústria da construção civil tem lidado nos últimos anos com modificaçôes substanciais, acarretadas devido ao crescente grau de competiçáo existente entre as empresas do setor no país. A globalização dos mercados, a elevação no nível de exigência por parte dos consumidores, entre outros aspectos, têm estimulado as empresas a buscar melhores níveis de desempenho através de investimentos em gestão e tecnologia da produção. Assim, a exemplo do que vem ocorrendo em outros setores industriais, a função produção vem adquirindo um papel cada vez mais estratégico na determinaçáo do grau de competitividade das empresas de construção civil (SARCINELLI, 2008).

O modelo de gestáo utilizado por grande parte das construtoras é baseado em processos de conversão, que transformam insumos em produtos intermediários ou finais, porém essa definição de produção tem ignorado muitas vezes algumas atividades que compóem os fluxos físicos entre as atividades de conversão, como por exemplo, a movimentaçáo de materiais, de pessoas e informaçóes. Essas atividades são caracterizadas por náo agregar valor ao produto (KOSKELA, 1992).

As consequências dessa gestão podem ser observadas na situação atual da construção civil, que é conhecida por possuir uma elevada quantidade de atividades que não agregam valor, baixa produtividade e alto desperdício de pessoas e matéria-prima. Esses problemas não se limitam à cadeia produtiva, se sobressaem também no setor gerencial, caracterizando um atraso do setor que se mostra fragmentado e pouco transparente (ARANTES, 2010).

Em busca de compreender e atender esse novo mercado, as empresas construtoras se veem obrigadas a repensar suas formas de produção, revendo suas estruturas gerenciais e conscientizando-se da necessidade de modificar conceitos. Dessa forma, torna-se necessário o setor evoluir como um todo, desde o canteiro de obras até o setor gerencial das empresas construtoras.

Nesse cenário aparece então uma nova filosofia conhecida por Lean Construction (Construção Enxuta), termo que vem sendo usado, desde 1993, pelo International Group for Lean Construction, referindo-se à aplicaçáo de algumas técnicas e ferramentas do sistema de Produçáo Enxuta no setor da construção civil. Essa nova filosofia de produçáo compreende os processos como a interação de atividades de conversão e de fluxo, onde as primeiras devem ser melhoradas e as de fluxo minimizadas, ou eliminadas, quando possível.

\section{SISTEMA TOYOTA DE PRODUÇÃO - STP}

Após a Segunda Guerra Mundial boa parte da mão de obra da Toyota teve que ser demitida, devido a crise gerada pela restrição de crédito. Dessa forma, com mão de obra reduzida e poucos recursos à disposiçáo para investimentos, os profissionais japoneses buscaram desenvolver um sistema que vinculava os benefícios da produção artesanal com operários altamente qualificados e ferramentas flexíveis para produzir precisamente o que o consumidor desejava, ou seja, as vantagens da produção em massa, com elevada produtividade e baixo custo (WOMACK; JONES, 2003). Sendo assim, a Toyota alcançou o fluxo contínuo em uma linha de produção de baixo volume, aprendendo a mudar rapidamente as ferramentas de um produto para o próximo, e reduzindo o dimensionamento das máquinas de maneira que diversos tipos de passos do processo pudessem ser concretizados imediatamente uns após os outros, conservando um fluxo contínuo do produto (WOMACK; JONES, 2003).

De acordo com Ghinato (2000), o STP é sustentado por dois pilares: a Autonomaçáo e o Just-in-time. Segundo Shingo (1996), a Autonomação é uma forma de possibilitar mecanismos como parar a máquina para que ela interrompa a produçáo quando se deparar com algum problema, impedindo que haja erros reproduzidos em série. E de acordo com o mesmo autor, o Just-in-time é um fator que solicita a produçáo com 
estoques mínimos, onde o aumento da produção é alcançado através da eliminação das perdas.

Trabalhando com estoques mínimos têm-se a possibilidade de uma melhor visualização da produção e detecção de possíveis problemas.

O conceito da filosofia Lean (enxuta) parte do princípio de que há desperdício em todos os lugares em uma organização e ter a mentalidade enxuta é direcionar a empesa para fazer cada vez mais com cada vez menos, e sempre com a finalidade de oferecer aos clientes o que eles realmente desejam no tempo que necessitarem, tornando as empresas mais flexíveis e capazes de responder efetivamente às necessidades dos clientes e ainda conseguir desenvolver, produzir e distribuir produtos com menos esforço humano, espaço, recursos, tempo e despesas globais (MORAES e SAHB, 2004).

Segundo Womack e Jones (1996), o pensamento enxuto é "uma forma de especificar valor, alinhar na melhor sequência as açóes que criam valor, realizar essas atividades sem interrupção toda vez que alguém as solicita e realizá-las de forma cada vez mais eficaz". A Figura 1 representa a influência da mentalidade enxuta nas organizaçóes.

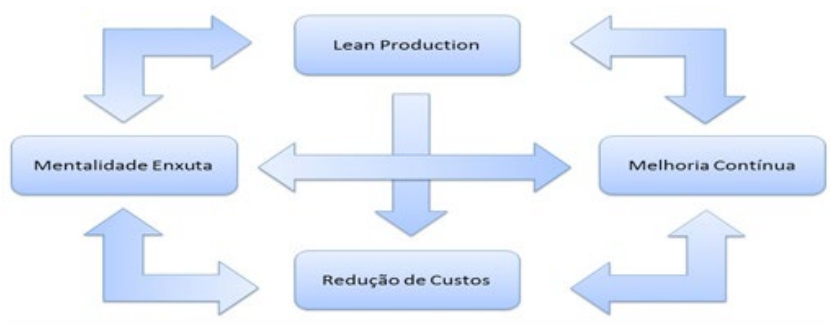

Figura 1 - Diagrama esquemático da influência da mentalidade enxuta

Fonte: adaptado de SILVA FILHO (1998).

Conforme Moraes e Sahb (2004), na prática, os benefícios que a filosofia Lean propicia às empresas são conseguidos principalmente por meio de:

- Produção integrada, com pequenos estoques, usando gerenciamento JIT;

- Produção puxada pelos clientes (ao invés de empurrada);

- Ênfase na prevenção e no controle da qualidade, em lugar da detecção ou correção;

- Trabalho organizado em equipes;

- Equipes polivalentes dedicadas à eliminaçáo de atividades que não agregam valor;
- Integraçáo de toda a rede de suprimento, desde a matéria-prima até o cliente final.

É interessante apresentar uma análise comparativa (Quadro 1) que mostre as vantagens da Produção Enxuta sobre a produção convencional, em termos de reduçáo de desperdícios e aumento da produtividade (ALVES, 2000).

Quadro 1 - Diferenças entre a produção em massa e a Produção Enxuta

\begin{tabular}{|c|c|}
\hline $\begin{array}{c}\text { PRODUÇÃO EM } \\
\text { MASSA }\end{array}$ & PRODUÇÃO ENXUTA \\
\hline $\begin{array}{l}\text { Elevado número } \\
\text { de trabalhadores } \\
\text { indiretos. }\end{array}$ & $\begin{array}{l}\text { Inexistência de } \\
\text { trabalhadores indiretos. }\end{array}$ \\
\hline \begin{tabular}{|l} 
Existência de espaço \\
para as áreas de \\
reparos e estoques.
\end{tabular} & $\begin{array}{l}\text { Quantidade de espaço } \\
\text { mínima dentro da } \\
\text { fábrica, para facilitar a } \\
\text { comunicação e evitar } \\
\text { os estoques; quase } \\
\text { inexistência de áreas de } \\
\text { retrabalho. }\end{array}$ \\
\hline $\begin{array}{c}\text { Distribuição de } \\
\text { trabalho desigual - } \\
\text { ritmos de produção } \\
\text { diferentes. }\end{array}$ & $\begin{array}{c}\text { Peças fluindo } \\
\text { uniformemente, e tarefas } \\
\text { de produçáo com ritmo } \\
\text { equilibrado. }\end{array}$ \\
\hline $\begin{array}{l}\text { Produçáo em } \\
\text { grandes lotes. }\end{array}$ & $\begin{array}{c}\text { Produçáa em pequenos } \\
\text { lotes. }\end{array}$ \\
\hline $\begin{array}{c}\text { Elevadas } \\
\text { quantidades de } \\
\text { estoque junto às } \\
\text { estaçóes de trabalho. }\end{array}$ & $\begin{array}{c}\text { Inexistência de } \\
\text { almoxarifados de peças; } \\
\text { e junto às estações de } \\
\text { trabalho encontram-se } \\
\text { apenas as quantidades de } \\
\text { peças requisitadas. } \\
\end{array}$ \\
\hline $\begin{array}{l}\text { Pouca flexibilidade - } \\
\text { máquinas dedicadas } \\
\text { (exigem tempo } \\
\text { para a realização } \\
\text { de modificaçóes no } \\
\text { tipo de produto a } \\
\text { ser fabricado). } \\
\end{array}$ & $\begin{array}{l}\text { Existência de flexibilidade } \\
\text { na produção devido aos } \\
\text { baixos tempos de setup. } \\
\text { Diferentes produtos } \\
\text { podem ser fabricados, } \\
\text { em curtos intervalos de } \\
\text { tempo. } \\
\end{array}$ \\
\hline $\begin{array}{c}\text { Investigação e } \\
\text { correção de defeitos } \\
\text { no produto acabado } \\
\text { (retrabalho). }\end{array}$ & $\begin{array}{l}\text { Investigação e correção } \\
\text { do problema, até a última } \\
\text { causa ( } 5 \text { porquês), antes } \\
\text { que o erro se propague na } \\
\text { linha de montagem. }\end{array}$ \\
\hline \begin{tabular}{|c|} 
Somente os gerentes \\
sêniores podem \\
parar a linha. \\
\end{tabular} & $\begin{array}{l}\text { Os trabalhadores podem } \\
\text { parar a linha quando um } \\
\text { problema é encontrado. }\end{array}$ \\
\hline
\end{tabular}

Fonte: adaptado de WOMACK et al., (1992) 
O que se espera da Lean Production (Produção Enxuta) é a produção de uma larga variedade de produtos, a baixos custos e com alta qualidade, com a menor quantidade possível de recursos. Dando flexibilidade à produção, agregando valor as atividades dos operários, eliminando perdas e desperdícios. Segundo Womack e Jones (1996), os cinco princípios da Lean Production são: valor, fluxo de valor, fluxo contínuo, produção puxada e perfeição. Esses princípios são adotados quando a empresa busca a eliminação ou a minimização das açôes que não agregam valor para os clientes.

Perdas podem ser observadas quando equipamentos, materiais e mão-de-obra são utilizados em números maiores do que as necessárias para a produção de um produto. Podendo ser observado tanto o desperdício de materiais quanto a execução de atividades desnecessárias. Para Hines e Taylor (2000) as atividades podem ser classificadas em: atividades que agregam valor; atividades que não agregam valor; e atividades que não agregam valor, mas são necessárias.

Ainda de acordo com Hines e Taylor (2000), é afirmado que a grande maioria das atividades é classificada como atividades que não agregam valor. Uma pesquisa realizada por eles mostram que em ambientes de manufatura, 5\% do tempo é gasto com atividades que agregam valor, enquanto que nos setores administrativos essas atividades representam apenas $1 \%$ do tempo total.

As atividades que não agregam valor são consideradas como desperdícios e conforme Shingo (1996) são classificadas em sete categorias:

a) Superprodução - perdas por produção superior àquela esperada, ou seja, consiste em produzir mais do que o necessário ou cedo demais, gerando um excesso que se transforma em custos. Esse desperdício origina a maioria dos outros desperdícios seguintes.

b) Espera - perdas de tempo enquanto o produto está sendo convertido. É o desperdício relacionado a tempo inativo de operadores, peças e informaçốes.

c) Transporte - perdas em tempo e esforço para o transporte de produtos e materiais resultando em gastos desnecessários.

d) Processamento - perdas no próprio processamento do produto. Classifica os processos que são utilizados ferramentas inadequadas.

e) Estoque - perdas no uso de uma grande quantidade de estoque, que mobiliza ca- pital, mão-de-obra, espaço físico, entre outros. Resultando em custos excessivos e baixo desempenho no serviço prestado ao cliente.

f) Desperdício nos movimentos - perdas na realização de um número superior ao necessário de movimentos para realizar uma tarefa devido à desorganização do ambiente.

g) Desperdício na elaboração de produtos defeituosos - erros frequentes no processo de informação, problemas na qualidade do produto ou baixo desempenho na entrega.

Stefanelli (2007) relaciona algumas possíveis causas de desperdícios e suas possíveis soluçôes no Quadro 2.

\section{CONSTRUÇÃO CIVIL}

O setor da construção civil representa significativa importância no contexto nacional, seja por sua representatividade econômica ou mesmo a social. Atualmente

a construção encontra-se em rápido processo de industrializaçáo embora muitos processos de trabalho continuem ainda sendo realizados de forma artesanal. Enquanto os projetos, a especificação de materiais e as técnicas construtivas tendem a se sofisticar dia-a-dia, a execução, as ferramentas e as condiçóes de trabalho nos canteiros de obras permanecem, em muitos casos, rudimentares, sendo empregados métodos e formas de trabalhos improvisados (FRANCO, 2001).

\section{CENÁRIO ATUAL NA BAHIA}

No Estado da Bahia, de acordo com dados colhidos junto ao IBGE na Pesquisa Anual da Indústria da Construção - PAIC

2007, a Indústria da Construção Civil apresenta uma receita líquida da ordem de $\mathrm{R} \$ 5$ bi/ ano, com custo de mão-de-obra de aproximadamente $37 \%$.

A construção civil baiana acompanha a expansão do setor em todo o País. Em 2010, o PIB do setor no Estado cresceu 14,6\%.

No segundo trimestre de 2011 esse crescimento foi de $4,8 \%$.

De acordo com os dados do Cadastro Geral dos Empregados e Desempregados (CAGED) divulgados pelo Ministério do Trabalho e Emprego (MTE), a Bahia, em 2010, foi responsável pela 
Quadro 2 - Causas e soluções para os tipos de desperdícios

\begin{tabular}{|c|c|c|}
\hline \multicolumn{3}{|c|}{ CAUSAS E SOLUÇÓES PARA OS TIPOS DE DESPERDÍCIOS } \\
\hline Desperdícios & Possíveis causas & Possíveis soluçóes \\
\hline \multirow{3}{*}{ Superprodução } & Áreas grandes de depósitos & Reduzir o setup \\
\hline & Custos elevados de transporte & Fazer só o necessário \\
\hline & Falhas no Planejamento & "Puxar" a produção \\
\hline \multirow{4}{*}{ Espera } & Espera por materiais & Sincronizar o fluxo de material \\
\hline & Espera por informaçôes & $\begin{array}{c}\text { Balancear a linha com trabalhadores } \\
\text { flexíveis }\end{array}$ \\
\hline & Layout inadequado & \multirow{2}{*}{ Realizar manutenção preventiva } \\
\hline & Imprevistos de produção & \\
\hline \multirow{3}{*}{ Transporte } & Layout inadequado & $\begin{array}{l}\text { Projetar layout para minimização do } \\
\text { transporte }\end{array}$ \\
\hline & Lotes grandes & \multirow[b]{2}{*}{ Reduzir a movimentação de material } \\
\hline & $\begin{array}{l}\text { Produção com grande } \\
\text { antecedência }\end{array}$ & \\
\hline \multirow{4}{*}{ Processos inadequados } & $\begin{array}{c}\text { Ferramentas e dispositivos } \\
\text { inadequados }\end{array}$ & Analisar e padronizar processos \\
\hline & Falta de padronização & \multirow{3}{*}{$\begin{array}{l}\text { Garantir a qualidade do material, } \\
\text { ferramentas e dispositivos }\end{array}$} \\
\hline & Material inadequado & \\
\hline & Erros ao longo do processo & \\
\hline \multicolumn{3}{|c|}{ CAUSAS E SOLUÇÔES PARA OS TIPOS DE DESPERDÍCIOS } \\
\hline Desperdícios & Possíveis causas & Possíveis soluçóes \\
\hline \multirow{6}{*}{ Estoque } & \multirow{2}{*}{ Aceitar superprodução } & Sincronizar o fluxo \\
\hline & & Reduzir o setup \\
\hline & \multirow[b]{2}{*}{ Produto obsoleto } & Reduzir lead times \\
\hline & & $\begin{array}{l}\text { Realizar a produção acompanhando a } \\
\text { demanda }\end{array}$ \\
\hline & \multirow[t]{2}{*}{ Grande flutuação da demanda } & $\begin{array}{l}\text { Promover a utilização do projeto } \\
\text { modular dos produtos }\end{array}$ \\
\hline & & Reduzir os demais tipos de desperdícios \\
\hline \multirow{4}{*}{ Movimentação } & Layout inadequado & Realizar estudo de movimentos \\
\hline & $\begin{array}{c}\text { Padróes inadequados e } \\
\text { ergonomia }\end{array}$ & Reduzir deslocamentos \\
\hline & $\begin{array}{l}\text { Disposição e/ou controle } \\
\text { inadequado de peças, matéria- } \\
\text { prima, material de consumo, } \\
\text { ferramentas e dispositivos }\end{array}$ & \multirow[t]{2}{*}{ Adotar sistemas de controle pertinentes } \\
\hline & Itens perdidos & \\
\hline \multirow{3}{*}{ Defeitos } & $\begin{array}{l}\text { Processos de fabricação } \\
\text { inadequados }\end{array}$ & $\begin{array}{l}\text { Utilizar mecanismos de prevenção de } \\
\text { falhas }\end{array}$ \\
\hline & Falta de treinamento & \multirow{2}{*}{ Não aceitar defeitos } \\
\hline & Matéria-prima defeituosa & \\
\hline
\end{tabular}

Fonte: adaptado de STEFANELLI ( 2007) 
geração de 123.947 vagas formais de trabalho. A construção civil foi responsável por $22,8 \%$ destas vagas. No período de janeiro a outubro de 2011, o número de vagas formais do setor da construção civil na Bahia, foi igual a 10.176. Segundo dados levantados pela Siduscon-BA (2011) a Bahia foi o estado que teve maior participaçáo do total de financiamentos imobiliários no Nordeste $(35,6 \%)$ no período de janeiro a setembro de 2011.

\section{LEAN CONSTRUCTION (CONSTRUÇÁO ENXUTA)}

Segundo Koskela (1992), a Lean Construction, também conhecida como Nova Filosofia de Produção (NFP), foi desenvolvida com base no sistema de produção da indústria automobilística, porém adaptada para a construção civil. $\mathrm{O}$ modelo de processo da Construção Enxuta consiste em um fluxo de materiais, desde a matéria-prima até o produto final, sendo o mesmo composto por atividades de transporte, espera processamento e inspeção, conforme demonstrado na Figura 2.

O que os diferenciam é o fato do novo modelo de processo de produçáo considerar tanto as etapas de conversão de espera, processamento e inspeção, essenciais para o aumento da matéria prima em produto quanto o fluxo das atividades, como movimentaçáo, produtividade, visando melhor desempenho com menores desperdícios.

Outra característica que diferencia é o valor está relacionado à satisfaçáo do cliente, tanto interno quanto externo, sendo isto essencial para a execução do processo. (TOMMELEIN, 2004)

De acordo com Koskela (1992), existe na construção civil outro tipo de fluxo na produção, além dos fluxos de montagem, de materiais e informaçôes, que também precisa ser gerenciado com atenção, denominado fluxo de trabalho, referente a todas as operaçóes exercidas pelas equipes no canteiro de obras. A operaçáo, neste contexto, refere-se ao trabalho realizado por equipes ou máquinas. É interessante destacar que algumas operaçóes podem estar fora do fluxo de materiais, como, por exemplo, manutenção de equipamentos, limpeza, etc. Por outro lado, algumas atividades do processo náo envolvem operaçóes, como é o caso de espera (estocagem) de materiais. O mesmo autor apresenta onze princípios que auxiliam na gestão de processos. Estes estão descritos a seguir:

1. Reduzir o número de atividades que não agregam valor: permitindo aumento da eficiência e reduçáo das perdas dos processos, não apenas por meio da melhoria do desempenho das atividades de conversão e de fluxo, mas também pela eliminação de algumas das atividades.

2. Aumentar o valor da saída considerando os requisitos do cliente: devem-se identificar claramente as necessidades dos dois tipos de clientes, o cliente final e o cliente da atividade posterior, e esta informação deve ser considerada no projeto do produto e na gestão da produção.

3. Reduzir a variabilidade: do ponto de vista da gestão de processos, existem duas razóes para a redução da variabilidade. Primeiramente, um produto uniforme em geral traz mais satisfação aos clientes, pois a qualidade do produto efetivamente corresponde às especificaçóes previamente estabelecidas. Em segundo lugar, a variabilidade tende a au-

Figura 2 - Modelo do processo de Lean Construction

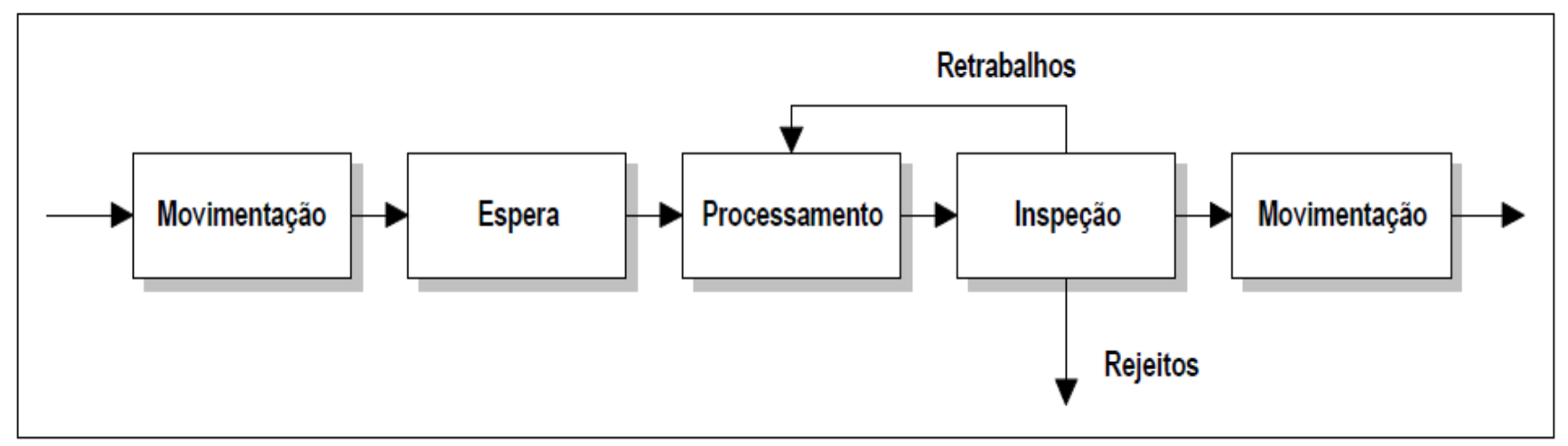

Fonte: adaptado de KOSKELA (1992) 
mentar a parcela de atividades que não agregam valor e o tempo necessário para executar um produto. A utilização de processos padronizados reduz a variabilidade tanto nas atividades de conversáo como nas de fluxo;

4. Reduzir o tempo de ciclo: este é um princípio que tem origem na filosofia Just in Time. A aplicação deste princípio está relacionada à necessidade de reduzir o tempo disponível como mecanismo de forçar a eliminação das atividades de fluxo e, baseado na compressão do tempo das atividades de inspeção, espera e movimentação, é possível obter uma redução. A redução do tempo de ciclo também leva a outras vantagens: entrega mais rápida ao cliente; maior facilidade na gestão dos processos; o efeito aprendizagem tende a aumentar; maior precisão na estimativa de futuras demandas; e maior flexibilidade.

5. Simplificar através da minimização do número de passos e partes: um sistema complexo apresenta custo superior, além de ser menos confiável do que sistemas simples. Este princípio é frequentemente utilizado no desenvolvimento de sistemas construtivos racionalizados. Isto ocorre em função das tarefas auxiliares de preparação e conclusão necessárias para cada passo no processo e também pelo fato de que, em presença de variabilidade, tende a aumentar a possibilidade de interferências entre as equipes.

6. Aumento da flexibilidade das saídas: este princípio também está vinculado ao conceito de processo como gerador de valor e pode ser alcançado por meio da reduçáo do tamanho de lotes até praticamente se equivaler à demanda, reduzir a dificuldade de setups e mudanças, customizar o mais tarde possível e treinar trabalhadores em várias tarefas.

7. Aumento da transparência do processo: o aumento da transparência de processos tende a tornar os erros mais fáceis de serem identificados no sistema de produçáo, ao mesmo tempo em que aumenta a disponibilidade de informaçóes, necessárias para a execução das tarefas, facilitando o trabalho. Este princípio pode também ser utilizado como um mecanismo para aumentar o envolvimento da mão de obra no desenvolvimento de melhorias.
8. Focar controle em todo o processo: há pelo menos dois pré-requisitos para focar controle no processo, primeiramente todo o processo deve ser medido e em segundo lugar deve haver um responsável pelo controle de todo o processo.

9. Introduzir melhoria continua ao processo: a redução do desperdício e o aumento de valor são atividades interativas e devem ser feitas continuamente. Há alguns métodos para institucionalizar a melhoria contínua, como a medição e o monitoramento das melhorias, o estabelecimento de metas esticadas, a atribuição de responsabilidade sobre as melhorias a todos os operários, o desafio constante na busca de melhores caminhos, e a ligação das melhorias ao controle.

10. Balancear melhoria nos fluxos por meio de melhoria nas conversóes: fluxos melhorados requerem menos capacidade na conversão; fluxos mais controlados tornam a implantação de novas tecnologias de conversão mais fáceis e essas podem gerar baixa variabilidade, beneficiando os fluxos.

11. Benchmark: trata de uma pesquisa no mercado para buscar possibilidades de melhorias através do conhecimento das técnicas da concorrência. Para tal é necessário conhecer o processo, conhecer os líderes industriais ou concorrentes, descobrindo, compreendendo e comparando as melhores práticas. Assim sendo, atingir a superioridade combinando as forças existentes com as melhores práticas externas.

\section{MÉTODO}

Com a finalidade de atingir os objetivos definidos neste estudo, o método de pesquisa utilizado foi desenvolvido sob dois enfoques. Primeiramente foram selecionadas fontes bibliográficas para a realização da referencial teórico abordando o Sistema Toyota de Produção (STP), o cenário da construção civil na Bahia e os princípios da filosofia Lean Construction. Posteriormente, foi utilizado um questionário, elaborado com base no levantamento bibliográfico, na realização de uma pesquisa de campo. $\mathrm{O}$ estudo se desenvolveu em quatro empresas construtoras de edificaçóes verticais localizadas na cidade de Itabuna - BA. A escolha foi por construtoras de médio porte, a fim de 
verificar, se as mesmas utilizam ou não a filosofia Lean em seus processos.

As entrevistas acompanhadas do questionário semiaberto foram os meios utilizados para coletar dados necessários à pesquisa. Estas foram realizadas sempre por uma mesma pessoa, a pesquisadora, e destinavam-se ao gerente da obra. Desta forma, o questionário confeccionado apresentou a seguinte composição:

1. Informaçóes gerais da empresa: considerou informações sobre a estrutura, tempo de mercado, empreendimentos realizados, tempo de existência, número de funcionários e aspectos de certificação e qualidade.

2. Aspectos da filosofia Lean Construction: questóes elaboradas com base nos onze princípios da Lean Construction.

\section{APRESENTAÇÁO E ANÁLISE DOS RESULTADOS}

\section{PERFIL DAS EMPRESAS}

Para cada empresa envolvida foi atribuída uma identificação, as empresas serão denominadas por construtora A, B, C e D.

As construtoras visitadas são caracterizadas pela estrutura organizacional que é dividida em departamentos. São eles: diretoria, projetos, engenharia, qualidade, administrativo, financeiro, segurança e produção. Todas possuem um quadro funcional com mais de 300 funcionários.

As construtoras $\mathrm{A}$ e $\mathrm{D}$ são caracterizadas pela administração familiar e as construtoras $\mathrm{B}$ e C pela administração profissional.

Quadro 2: Características das empresas

\begin{tabular}{|c|c|c|c|c|}
\hline $\begin{array}{c}\text { Característica } \\
\text { Analisada }\end{array}$ & Empresa A & Empresa B & Empresa C & Empresa D \\
\hline $\begin{array}{c}\text { Tipo de } \\
\text { administração }\end{array}$ & Familiar & Sócios/Diretores & Sócios/Diretores & Familiar \\
\hline Ano de fundação & 1985 & 1989 & 2007 & 2001 \\
\hline $\begin{array}{l}\text { Quantidade de } \\
\text { colaboradores }\end{array}$ & Entre 300 a 350 & 320 & Entre 300 a 350 & Entre 300 a 350 \\
\hline Empreendimentos & $\begin{array}{c}18 \text { entregues, } 8 \\
\text { em execução e } 3 \\
\text { lançamentos }\end{array}$ & $\begin{array}{c}35 \text { entregues, } 3 \\
\text { em execuçáo e } 2 \\
\text { lançamentos }\end{array}$ & $\begin{array}{c}3 \text { entregues, } 3 \\
\text { em execução e } 3 \\
\text { lançamentos }\end{array}$ & $\begin{array}{c}11 \text { entregues, } 5 \\
\text { em execução e } 2 \\
\text { lançamentos }\end{array}$ \\
\hline Segmento & $\begin{array}{c}\text { Condomínios } \\
\text { para classe média } \\
\text { e alta }\end{array}$ & Obras públicas & $\begin{array}{c}\text { Obras públicas e } \\
\text { privadas }\end{array}$ & $\begin{array}{l}\text { Obras públicas e } \\
\text { privadas }\end{array}$ \\
\hline Certificação & Não possui & $\begin{array}{c}\text { ISO-9001/2008 } \\
\text { Nível A/PBQP-H e } \\
\text { Atestado QUALIOP }\end{array}$ & $\begin{array}{c}\text { ISO-9001/2009 } \\
\text { Nível A/PBQP-H }\end{array}$ & Nível C/ PBQP-H \\
\hline
\end{tabular}

A construtora A tem o segmento bem definido utilizando-se do sistema condominial. Já as construtoras $\mathrm{B}, \mathrm{C}$ e D constroem de acordo com os contratos adquiridos junto a Caixa Econômica Federal.

O sistema de qualidade das construtoras é assegurado pela certificação ISO - 9001 e pelo nível A do PBQP-H (Programa Brasileiro de Qualidade e Produtividade do Habitat).
PRINCÍPIOS DA FILOSOFIA LEAN CONSTRUCTION NAS EMPRESAS ESTUDADAS

\section{Princípio - Reduzir atividades que não agregam valor:}

Nas empresas A e B não existem um método definido para a análise das atividades que não agregam valor, o que se faz é utilizar o procedimento mais adequado, buscado na literatura, quando é identificada a necessidade de análise de 
algum fluxo ou atividade. Observou-se que essas empresas visam acelerar seus processos e náo se preocupam com as atividades que não agregam valor, pois executa etapas da obra sabendo que haverá retrabalho, como exemplo, a colocação das placas de gesso dos tetos dos banheiros sem obedecer ao pré-requisito das instalaçóes elétricas.

As empresas $\mathrm{C}$ e $\mathrm{D}$ também não utilizam nenhum método específico para identificar as atividades que não agregam valor, mas se preocupam em minimizar ou até eliminar essas atividades. Como exemplo na empresa C, o estoque de blocos de concreto que antes era estocado do lado de fora da obra, passou a ser estocado perto do elevador de carga. Já na empresa $\mathrm{D}$, sáo tomadas açóes constantemente. Como exemplo, a utilizaçáo de um dispositivo para sustentar o mangote utilizado no bombeamento da argamassa para contra piso, enquanto o pedreiro espalha a massa. Deixando assim, o servente livre para exercer outra atividade.

\section{2o Princípio - Aumento do valor do produto/ serviço a partir das consideraçóes dos clientes:}

Percebeu-se que empresa A tem esse princípio aplicado parcialmente, pois só são consideradas as necessidades dos clientes internos. A empresa conta com uma pesquisa de mercado para identificar como será a configuraçáo do projeto de cada novo empreendimento. A inexistência do departamento de gestão da qualidade e a falta de certificação ISO 9001 na empresa é observado com principal dificuldade de manter esse princípio ativo.

Nas empresas B, C e D foram identificadas algumas atividades desenvolvidas que comprovam a aplicação desse princípio. Sáo elas:

- As necessidades dos clientes internos e externos são consideradas no planejamento de seus projetos;

- Antes da entrega de qualquer empreendimento é feito uma vistoria acompanhada de um check list padrão;

- Existe uma equipe de manutenção para reparar o serviço determinado;

- Entrega o manual do proprietário;

- Existe pesquisa para avaliar o nível de satisfação.

- A retroalimentaçáo do processo é feita entre os departamentos, onde qualquer mudança de projeto é informada à equipe responsável pela execução.

\section{Princípio - Reduzir a variabilidade do processo:}

Com relação a esse princípio percebe-se que nas empresas certificadas pela ISO 9001, o controle dos materiais e a padronização dos processos são comuns, pois são procedimentos da norma para a certificação. Dessa forma, observou-se que as empresas $\mathrm{B}, \mathrm{C}$ e $\mathrm{D}$ utilizam processos padronizados, inspecionam os materiais no momento do recebimento e verificam os pré-requisitos antes de iniciar outra etapa do processo como forma de diminuir a variabilidade nos seus processos. Já na empresa A esse princípio não é identificado.

\section{4o Princípio - Reduzir o tempo de ciclo:}

Todas as empresas elencaram diversas causas para ocorrência de atrasos das atividades. As principais causas citadas são: a escassez de mão de obra especializada, incumprimento do prazo de entrega pelo fornecedor, falta de programação dos materiais, condiçôes climáticas adversas, atraso de pagamentos; problemas com empreiteiros; baixa produtividade de mão de obra, alteraçáo/mudança de tarefas, baixa capacidade produtiva e as tomadas de decisóes. Apesar das empresas apresentarem atrasos nas atividades com uma determinada frequência, apenas a empresa $\mathrm{D}$ enxerga a necessidade de reduzir o tempo de ciclo. As demais empresas não buscam eliminar as atividades de fluxo que fazem parte do ciclo de produçáo. Portanto, o princípio não foi identificado nas empresas já que foram identificadas dificuldades na execução do PCP (Planejamento e Controle da Produçáo) pelos gerentes das obras, onde existe um número grande de precedências entres as atividades, de forma que essas não podem ser executadas em paralelo, consequentemente aumenta-se o tempo de ciclo.

\section{Princípio - Simplificar através da redução de passos ou partes:}

As empresas estudadas B, C e D reduzem as partes ou passos para simplificar os processos com o objetivo de racionalizar o sistema construtivo.

Algumas atividades citadas por essas empresas com a finalidade de simplificar seus passos são: execução da alvenaria em menos tempo através de tarefas programadas com os colaboradores, visando acelerar a produçáo e diminuir o tempo 
de ciclo; a utilização de vergas pré- moldadas, possibilitando a redução significativa no número de passos, pois o próprio pedreiro pode posicioná-la, ao longo da execução de alvenaria e o emprego de lajes pré-moldadas, que são estocadas no pátio de lajes e quando solicitadas são içadas para o local.

Percebeu-se que essas empresas consideram a simplificação muito importante, pois quando o sistema é complexo, o custo é maior e a confiança é menor. Já a empresa A não aplica esse princípio. Portanto, o número de atividades que não agregam valor tende a ser maior devido ao maior número de componentes ou passos num processo.

\section{6o Princípio - Aumentar a flexibilidade de saída:}

Nas empresas A e B, a flexibilidade é permitida, o que significa que o cliente pode personalizar o projeto original. Porém, na empresa $B$ essa opção de mudança acontece em alguns dos seus empreendimentos. No caso da atual obra da empresa que é caracterizada por um padráo que atende aos requisitos do programa Minha Casa Minha Vida, não existe a possibilidade do cliente interferir, pois a construção é feita com blocos estruturais que constituem a estrutura resistente da edificação, impossibilitando a modificação do projeto.

Nas empresas C e D observou-se que existe tanto a flexibilidade permitida quanto com a planejada. A equipe responsável pelos projetos avalia a proposta de modificaçáo e apresenta o custo para tal serviço. O cliente é responsável por contratar seu próprio arquiteto. Existe um prazo para o cliente que tem interesse em fazer alguma modificação estipulado através do cronograma da empresa. Em todas as empresas em análise, existe também o treinamento para todos os colaboradores quando ingressam e quando iniciam quaisquer atividades voltadas para aperfeiçoamento dos serviços.

Percebeu-se que a possibilidade de alterar as características dos produtos entregues aos clientes, sem aumentar substancialmente os custos dos mesmos, confirma a aplicação desse princípio nas empresas em estudo.

\section{Princípio - Aumentar a transparência do processo:}

$\mathrm{Na}$ empresa $\mathrm{A}$, apesar de não existir certificado de qualidade, o programa $5 S$ é utilizado. Toda obra é sinalizada e há treinamentos de se- gurança assim que cada colaborador ingressa na empresa. O rádio comunicador é utilizado em contrapartida ao Kanban e o Andon.

Nas empresas B, C e D foram identificadas ações que comprovam a aplicação desse princípio. As principais são: A disponibilização das informaçôes de processo na área de trabalho, a sinalização adequada do ambiente de trabalho, a utilização de rádios para comunicação das equipes de trabalho, a disposição dos procedimentos de execução de serviços para todos os colaboradores e a organização do canteiro com fluxos ágeis e rotas definidas para materiais.

\section{Princípio - Focar controle em todo processo:}

Constatou-se nas empresas A, B e D que o princípio não é aplicado, uma vez que, as atividades do planejamento são desempenhadas sem atingir o objetivo geral, pois não existe uma pessoa responsável para controlar o processo, ou seja, não existe um método, técnica ou ferramenta para controlar o processo como um todo. Apesar de, existir a comunicação entre a equipe de planejamento e a de execução das atividades. Somente na empresa $C$, a cadeia produtiva é identificada proporcionando uma visão mais ampla, há parcerias com os fornecedores e existem pessoas responsáveis atentadas para o controle. Já que a visão sistêmica do problema como um todo é o foco desse princípio associado a parcerias (fornecedores como exemplo) e também a definição clara da responsabilidade pelo controle global do processo.

\section{$9^{\circ}$ Princípio - Introduzir melhoria continua ao processo:}

$\mathrm{Na}$ empresa A esse princípio foi identificado parcialmente, pois não tem um departamento ou pessoa responsável para gerar indicadores de desempenho, mas existe um programa de metas que visa o melhor resultado para a obra. Os colaboradores tem o conhecimento através de minipalestras ministrada pelo próprio engenheiro.

As empresas B, C e D aplicam o princípio através dos procedimentos de ação corretiva e preventiva que possibilitam a identificação de problemas no processo e suas prováveis causas. Esse procedimento encontra-se nas obras das três empresas, por ocasião da participação do PBQP-H (Programa Brasileiro de Qualidade de Produti- 
vidade do Habitat). Além disso, as empresas introduziram indicadores para medir seus processos principais. Como exemplo, o índice de atendimento as metas, satisfaçáo do cliente com o projeto, o número de ocorrências de incompatibilidade por projeto, cumprimento de prazos, a avaliação de fornecedores, velocidade de vendas, o índice de satisfação dos clientes, índice de competitividade.

\section{Princípio - Balancear melhoria nos fluxos por meio de melhoria nas conversóes:}

As empresas $\mathrm{A}$ e $\mathrm{B}$ não aplicam melhorias em seu fluxo. Na empresa B, observou-se que existe a necessidade de analisar seus fluxos de informações e de materiais, visto que a produção é o objetivo principal da obra. Portanto, esse princípio não foi identificado nessas empresas.

Percebeu-se que as empresas C e D utilizam esse princípio através das melhorias realizadas nos fluxos como, a aplicação do mapeamento dos processos e identificação de seus requisitos para cada estágio e a eliminaçáo de alguns processos de espera e de fluxo. Tendo em vista que, fluxos aperfeiçoados solicitam menos capacidade na conversão, fluxos mais controlados tornam a implantaçáo de novas tecnologias de conversão mais simples. Como exemplo, a empresa D utilizou a ferramenta de mapeamento no processo de montagem da laje nervurada e aplicou melhorias para eliminar alguns processos de espera e de fluxo.

\section{$11^{\circ}$ Princípio - Benchmarking:}

As empresas A e B não utilizam esse princípio, pois não fazem benchmarking. As empresas evidenciaram que utilizam de uma metodologia própria e que não aprendem com práticas de outras empresas. Já nas empresas $\mathrm{C}$ e $\mathrm{D}$, os responsáveis ressaltaram a importância de se fazer benchmarking e colocaram que é relevante conhecer todos os processos, para que estes possam ser melhorados, através de práticas de outras empresas. Existe a busca, o entendimento e a aplicação das boas práticas de outras empresas.

\section{CONSIDERAÇÓES FINAIS}

O Lean Construction, filosofia voltada para as empresas do setor da construçáo civil, adaptado a partir dos conceitos da Lean Production, indica alternativas para a melhoria dos processos construtivos e não se fundamenta apenas na implantação de novas tecnologias. Ela direciona esforços para a racionalizaçáo dos processos, através da otimização dos fluxos existentes entre as diversas atividades necessárias a execução da obra.

A partir da pesquisa realizada em quatro construtoras de médio porte na cidade de Itabuna/ BA identificou-se a realização de práticas relacionadas à filosofia Lean Construction. As evidências coletadas de melhorias no processo de produção foram observadas abrangendo cada um dos onze princípios da Lean Construction. Os resultados foram satisfatórios à filosofia para a maioria dos princípios analisados. Com a investigação ficou claro que as empresas estudadas são pressionadas pelas mudanças de mercado dos últimos anos e pela crescente exigência de utilização de critérios de qualidade e certificação. Por isso, adotaram procedimentos racionalizados de processos, buscando diminuir os desperdícios e aumentar a produtividade.

Em relação aos princípios que foram observados parcialmente nas empresas, percebeu-se que estes não são totalmente implantados porque as empresas, ainda, não enxergam necessidade de tais técnicas ou ferramentas. Há em grande parte dos entrevistados um sentimento de comodismo, demonstrando satisfação com a atual gestão dos seus processos e não demonstrando o interesse pelas melhorias trazidas pela implantação de outra forma de gestão. Essa mentalidade é contrária à filosofia, onde o sucesso da implantação dos princípios da Lean Construction depende do comprometimento da alta gerência, da priorizaçáo das necessidades da obra e do treinamento dos clientes internos. Portanto, as implantaçóes desses princípios devem partir primeiramente da conscientização dos mais altos níveis hierárquicos acerca da importância desta filosofia e tornar evidente o ganho que ela pode trazer para a organizaçáo.

A filosofia Lean não é algo que se estruture em um curto espaço de tempo, pois é necessário ser implantada de forma sistêmica em todas as áreas produtivas. Não ter um sistema de produção que possa sustentar a Lean Construction, equivale a uma aplicação isolada de suas ferramentas e métodos, não conseguindo medir os resultados reais fornecidos. Por esse motivo as empresas analisadas não conseguem obter os resultados esperados, por implantar apenas algumas das ferramentas em problemas pontuais e náo considerar todo o sistema. 
Através desta verificação observa-se a necessidade de se expandir os estudos referentes à filosofia Lean Construction, em específico ao que demonstre a redução dos custos como benefício. Sugerem-se outros estudos que mostrem e comprovem a eficácia das práticas da filosofia no setor da construção civil visando à sensibilização dos gestores das empresas desse setor.

\section{BIBLIOGRAFIA}

ALVES, T. C. L. Diretrizes para a gestão dos fluxos físicos em canteiros de obras: proposta baseada em estudo de caso. Dissertaçáo (mestrado em Engenharia Civil) - Curso de Engenharia Civil, Universidade Federal do Rio Grande do Sul, Porto Alegre, 2000.

ARANTES, F. T. Modelo de diagnóstico da maturidade da construção enxuta e estudo de casos em empresas da construção civil. São Carlos, 2010.

CBIC. Câmara Brasileira da Indústria da Construção. Construção Civil: Análise e Perspectivas.<http://www.cbicdados.com.br/> Acesso em 25/11/2011.

FRANCO, Eliete de Medeiros. Gestão do Conhecimento na Construção Civil: uma aplicação dos mapas cognitivos na concepção ergonômica da tarefa de gerenciamento dos canteiros de obras. Florianópolis. 250p. Tese (Doutorado em Engenharia de Produção) - Programa de Pós-Graduação em Engenharia de Produção, UFSC, 2001.

GHINATO, P. Produção \& Competitividade: Aplicaçóes e Inovaçóes, Ed.: Adiel T. de Almeida \& Fernando M. C. Souza, Edit. da UFPE, Recife, 2000. 6 p.

HINES, P.; TAYLOR, D. (2000). Going Lean. A guide to implementation. Lean Enterprise Research Center, Cardiff, UK.

IBGE, Instituto Brasileiro de Geografia e Estatística.<http://www.ibge.gov.br/> Acesso em 22/11/2011.

KOSKELA, L. Application of the new production philosophy to construction. Stanford, EUA, CIFE, 1992.
MORAES, J. A. R. de; SAHB, L. M. Manufatura Enxuta. 2004. Artigo disponível em < http:// www.ietec.com.br>. Acesso em 10/10/2011.

SARCINELLI, W. T. Construção enxuta através da padronização de tarefas e projetos. Vitória, ES, 2008.

SHINGO, S. O Sistema Toyota de produção: Do ponto de vista da engenharia de produçáo $2 \mathrm{ed}$. Porto Alegre: Artes Médicas, 1996. 291p.

SILVA FILHO, F. A. Da. Além da manutenção programada do trem em larga escala: uma adaptação do método "enxuto" de gestáo para manutenção programada do trem unidade elétrica (TUE). $\mathrm{O}$ caso Metrotec. Dissertação apresentada à Universidade Federal de Pernambucano para a obtenção do título de mestre em administração, PROPAD - CMA - UFPE. Recife. 1998.

SINDUSCON-BA. Sindicato da Indústria da Construção do Estado da Bahia. Construção civil na Bahia em números. 2011. <http://www. sinduscon-ba.com.br/> Acesso em: Janeiro/2012.

STEFANELLI, P. Utilização da Contabilidade dos Ganhos como Ferramenta para a Tomada de Decisão em um Ambiente com Aplicação dos Conceitos de Produção Enxuta. Trabalho de Conclusão de Curso - Escola de Engenharia de São Carlos - USP, 2007.

TOMMELEIN, I. D. The value chain: Adding value to the supply chain. Mechanical Contracting Education and Research Foundation (MCERF), Rockville, MD, USA, 2004. 28p.

WOMACK, J. D.; JONES, D. T.; \& ROOS, D. A Máquina que mudou o mundo. 2a.ed. Rio de Janeiro: Campus, 1992.

WOMACK, J. P. JONES, D. T. Lean thinking: Banish waste and create wealth in your Corporation. New York: Free Press, 2003.

Artigo submetido em 23/07/2012, aceito em $30 / 10 / 2012$ 